\title{
Iatrogenic Blood Loss in Very Low Birth Weight Infants and Transfusion of Packed Red Blood Cells in a Tertiary Care Neonatal Intensive Care Unit
}

\author{
Ahmed Aboalqez, Philipp Deindl, Chinedu Ulrich Ebenebe, Dominique Singer and Martin Ernst Blohm * \\ Division of Neonatology and Pediatric Intensive Care Medicine, University Children's Hospital, \\ University Medical Center Hamburg-Eppendorf, Martinistr. 52, 20246 Hamburg, Germany; \\ a.aboalqez@uke.de (A.A.); p.deindl@uke.de (P.D.); c.ebenebe@uke.de (C.U.E.); d.singer@uke.de (D.S.) \\ * Correspondence: m.blohm@uke.de
}

check for

updates

Citation: Aboalqez, A.; Deindl, P.; Ebenebe, C.U.; Singer, D.; Blohm, M.E. Iatrogenic Blood Loss in Very Low Birth Weight Infants and Transfusion of Packed Red Blood Cells in a Tertiary Care Neonatal Intensive Care Unit. Children 2021, 8, 847. https:/ / doi.org/10.3390/children 8100847

Academic Editor:

Bernhard Schwaberger

Received: 30 August 2021

Accepted: 23 September 2021

Published: 25 September 2021

Publisher's Note: MDPI stays neutral with regard to jurisdictional claims in published maps and institutional affiliations.

Copyright: (c) 2021 by the authors. Licensee MDPI, Basel, Switzerland. This article is an open access article distributed under the terms and conditions of the Creative Commons Attribution (CC BY) license (https:// creativecommons.org/licenses/by/ $4.0 /)$.

\begin{abstract}
An adequate blood volume is important for neonatal adaptation. The study objective was to quantify the cumulative iatrogenic blood loss in very low birth weight (VLBW) infants by blood sampling and the necessity of packed red cell transfusions from birth to discharge from the hospital. In total, 132 consecutive VLBW infants were treated in 2019 and 2020 with a median birth weight of $1180 \mathrm{~g}$ (range 370-1495 g) and a median length of stay of 54 days (range 0-154 days) were included. During the initial four weeks of life, the median absolute amount of blood sampling was 16.5 mL (IQR 12.3-21.1 mL), sampling volume was different with 14.0 mL (IQR 12.1-16.2 mL) for non-transfused infants and $21.6 \mathrm{~mL}$ (IQR 17.5-29.4 mL) for transfused infants. During the entire length of stay, $31.8 \%$ of the patients had at least one transfusion. In a generalized logistic regression model, the cumulative amount of blood sampling $(p<0.01)$ and lower hematocrit at birth $(p=0.02)$ were independent predictors for the necessity of blood transfusion. Therefore, optimized patient blood management in VLBW neonates should include sparse blood sampling to avoid iatrogenic blood loss.
\end{abstract}

Keywords: VLBW neonate; blood sampling; blood transfusion; iatrogenic blood loss

\section{Introduction}

An adequate circulatory volume is essential in perinatal transition and during the neonatal period [1]. During a regular physiological vaginal delivery, a placental blood transfusion to the newborn occurs in the period after the birth of the child, before the umbilical cord is clamped.

At delivery of a mature neonate, $70 \mathrm{~mL} / \mathrm{kg}$ blood, referring to the infant's body weight, are in the infant, and $35 \mathrm{~mL} / \mathrm{kg}$ in the placenta [2]. With delayed cord clamping, placental blood is shifted to the newly born infant resulting in a blood volume of approximately $93 \mathrm{~mL} / \mathrm{kg}$ body weight after three minutes [2]. This perinatal auto-transfusion of placental blood into the neonate appears to be a biologically useful mechanism to help perinatal adaptation [1-5], particularly for premature infants with their physiologically low absolute amount of blood volume.

Neonatal blood volume can be preserved by sparse blood sampling for diagnostic purposes. Iatrogenic neonatal blood loss in association with blood sampling [6-13] has been an issue for decades. Several studies have actually quantified the iatrogenic blood loss in VLBW neonates [6-11]. The amount of blood taken from ELBW and VLBW infants during the first 28 days of life has been reported as $31 \mathrm{~mL} / \mathrm{kg}$ body weight in 1981 [6], $50.3 \mathrm{~mL} / \mathrm{kg}$ body weight [7] in 1988, and $24.2 \mathrm{~mL} / \mathrm{kg}$ body weight in 2019 [8]. In a recent study published in 2020, the average cumulative $28 \mathrm{~d}$ blood loss in ELBW neonates with an umbilical artery catheter (UAC) in place was $69 \mathrm{~mL}(108 \mathrm{~mL} / \mathrm{kg})$ while the average cumulative blood loss without UAC in place was $32 \mathrm{~mL}(43 \mathrm{~mL} / \mathrm{kg})$ [9]. Different studies 
quantifying iatrogenic neonatal blood loss have in common, that smaller neonates (ELBW and VLBW) have a relatively higher amount of blood sampling in $\mathrm{mL} / \mathrm{kg}$ body weight than larger neonates [6-11]. Still, iatrogenic blood loss by blood sampling is one of the main factors for anemia in VLBW infants, leading to the necessity of packed red cell transfusions. Even in recent publications, approximately 50\% of VLBW neonates with a normal hematocrit at birth require at least one transfusion during their hospital stay [14]. This study aimed to quantify cumulative iatrogenic blood losses in VLBW neonates and correlate them to demographic and clinical outcome parameters and to blood transfusions. With this study, we want to raise awareness for good neonatal patient blood management [15] by preserving blood volume, starting at initial stabilization or resuscitation and then throughout the entire length of hospital stay of this patient population.

\section{Materials and Methods}

This observational study was conducted as a retrospective single-center study at a tertiary referral center (University Hamburg-Eppendorf Medical Center, Hamburg, Germany). We included VLBW and ELBW infants born in the University Medical Center Hamburg-Eppendorf during 2019 and 2020 into the analysis. Transfusion triggers for packed red cells were restrictive [16-18], based on the national guidelines, generally following the restrictive arm of the ETTNO trial [18]. Neonatal outcome parameters were defined as follows: Bronchopulmonary dysplasia (BPD) as additional oxygen demand at a corrected age of 36 weeks, intraventricular hemorrhage (IVH) in cases with IVH grade 3 or 4 , necrotizing enterocolitis (NEC) as Bell stage 2 and 3, retinopathy of prematurity (ROP) was defined by the necessity of intraocular vascular endothelial growth inhibitor (VEGFinhibitor) administration or laser treatment. Blood sampling, transfusion, and clinical and outcome data were extracted from the electronic patient data management system (PDMS ICM, Dräger, Lübeck, Germany). For individual types of laboratory tests (e.g., full blood count, clinical chemistry, drug level monitoring, clotting studies, blood gas analysis, blood samples for crossmatching packed red cells, neonatal metabolic screening, genetic testing) the amount of blood typically required in the setting of the neonatal intensive care unit (NICU) and blood losses in association with vascular access were defined as follows: blood gas analysis $100 \mu \mathrm{L}$, newborn screening $250 \mu \mathrm{L}$, full blood count $750 \mu \mathrm{L}$, infection screen including IL6 and CRP $750 \mu \mathrm{L}$, extended blood tests including liver and renal function tests $1000 \mu \mathrm{L}$, blood culture $500 \mu \mathrm{L}$, drug levels $750 \mu \mathrm{L}$, clotting studies $1300 \mu \mathrm{L}$, blood losses with the establishment of venous or arterial access $750 \mu \mathrm{L}$. The cumulative volume of all blood samples and losses for each patient during the entire hospital stay was then calculated based on the laboratory results in the PDMS. In total, 164 patients were eligible. Patients transferred to other hospitals or in-house wards not equipped with the electronic PDMS before discharge at home were excluded. Subsequently, 132 VLBW neonates were included in the analysis.

For statistical analysis with appropriate tests (Chi-Square test statistics and Fisher's exact test, pairwise Pearson correlation, t-test, generalized logistic regression model) $\mathrm{R}$ (Version 4.0.3, R Core Team, 2020) and SPSS (version 20, IBM Inc., Chicago, IL, USA) were used. Data collection and anonymized data handling were in concordance with the local Review Board (Ethik-Kommission Ärztekammer Hamburg, Germany, WF-075/21, 29 March 2021). 


\section{Results}

\subsection{Patients}

Data from 132 VLBW infants were included. Table 1 shows the demographic and outcome parameters of the studied sample cohort.

Table 1. Demographic and clinical characteristics of the study population sample.

\begin{tabular}{|c|c|}
\hline & Study Population $(n=132)$ \\
\hline Birth weight [g, median, IQR, range] & 1180 (IQR 903-1360, range 370-1495) \\
\hline $\begin{array}{l}\text { Gestational age } \\
\text { [weeks, median, IQR, range] }\end{array}$ & $29+5(\mathrm{IQR} 27+5$ to $31+2 ;$ range $23+5$ to $36+5)$ \\
\hline LOS [days, median, IQR, range] & 54 (IQR 35-74; range 0-154) \\
\hline Multiple gestation $[n ; \%]$ & $66(50 \%)$ \\
\hline Female sex $[n ; \%]$ & $63(47.7 \%)$ \\
\hline Delivery mode C-section & $121(91.7 \%)$ \\
\hline Sepsis/Infection $[n ; \%]$ & $39(29.5 \%)$ \\
\hline $\operatorname{IVH}[n ; \%]$ & $6(4.5 \%)$ \\
\hline $\operatorname{BPD}[n ; \%]$ & $6(4.5 \%)$ \\
\hline $\operatorname{ROP}[n ; \%]$ & $6(4.5 \%)$ \\
\hline $\operatorname{NEC}[n ; \%]$ & $4(3.0 \%)$ \\
\hline PDA treated medically & $28(21.2 \%)$ \\
\hline PDA treated operatively [ $n ; \%]$ & $4(3.0 \%)$ \\
\hline Fatal outcome $[n ; \%]$ & $6(4.5 \%)$ \\
\hline
\end{tabular}

\subsection{Blood Transfusion}

The rate of patients receiving at least one packed red cell transfusion during their hospital stay was $31.8 \%$. The cumulative blood transfusion volume during the entire hospital stay was $33.5 \mathrm{~mL}$ on average (IQR $20-53.75 \mathrm{~mL}$ ) in patients who received at least one transfusion. Patients with and without a blood transfusion were demographically different (Table 2) with a higher birth weight and gestational age and a shorter duration of stay in non-transfused patients.

Table 2. Demographic differences between transfused and non-transfused patients.

\begin{tabular}{cccc}
\hline Demographic Factor & Transfused Patients $(\boldsymbol{n}=\mathbf{4 2})$ & Non-Transfused Patients $(\boldsymbol{n}=\mathbf{9 0})$ & $\boldsymbol{p}(\boldsymbol{t}$-Test) \\
\hline Birth weight [g, median, IQR] & $755(643-943)$ & $1275(1074-1415)$ & $<0.001$ \\
Gestational age [weeks, median, IQR] & $26+2(25+3-29+5)$ & $30+2(28+5-31+5)$ & $<0.001$ \\
LOS [days, median, IQR] & $93(70-103)$ & $44(33-59)$ & $<0.001$ \\
\hline
\end{tabular}

Legend: IQR interquartile range; LOS length of stay.

\subsection{Blood Sampling}

The absolute amount of blood sampling is shown in Table 3. The median absolute amount of blood sampling [mL] during the initial four weeks of life was $16.5 \mathrm{~mL}$ (IQR 12.3-21.1 mL). Median sampling volume and median gestational age were different with $14.00 \mathrm{~mL}$ (IQR 12.05-16.20 mL)/gestational age $30+2$ weeks (IQR $28+5-31+5$ weeks) for non-transfused infants and $21.60 \mathrm{~mL}$ (IQR 17.51-29.40 mL)/26 + 2 weeks (IQR $25+3-$ $29+5$ weeks) for transfused infants. 
Table 3. Absolute cumulative blood sampling volume [ $n=132$ VLBW infants].

\begin{tabular}{ccc}
\hline $\begin{array}{c}\text { Postnatal Age } \\
\text { [Completed Weeks] }\end{array}$ & $\begin{array}{c}\text { Non-Transfused Patients } \\
\text { [mL; Median (IQR)] }\end{array}$ & $\begin{array}{c}\text { Transfused Patients } \\
\text { [mL; Median (IQR)] }\end{array}$ \\
\hline 0 & $6.18(4.73-7.35)$ & $8.20(6.60-9.95)$ \\
1 & $8.65(7.23-10.53)$ & $11.50(9.35-14.75)$ \\
2 & $10.33(8.43-12.69)$ & $14.98(11.86-18.95)$ \\
3 & $12.45(10.39-14.01)$ & $17.15(13.90-26.50)$ \\
4 & $14.00(12.05-16.20)$ & $21.60(17.51-29.40)$ \\
5 & $15.50(13.49-17.71)$ & $22.10(17.88-32.89)$ \\
6 & $17.68(15.93-20.64)$ & $23.20(19.10-35.95)$ \\
7 & $19.45(17.30-21.25)$ & $25.50(21.03-35.86)$ \\
8 & $20.90(18.74-24.84)$ & $30.83(23.25-41.79)$ \\
9 & $26.45(21.45-29.45)$ & $34.63(25.40-44.35)$ \\
10 & $31.45(29.10-33.25$ & $37.28(25.11-47.11)$ \\
11 & $33.60(32.08-35.13)$ & $39.45(29.50-49.00)$ \\
12 & $36.80(35.25-37.60)$ & $41.45(31.38-53.75)$ \\
13 & $36.23(35.01-37.44)$ & $44.70(34.70-55.10)$ \\
14 & & $49.75(43.99-60.01)$ \\
15 & & $59.90(45.70-70.05)$ \\
16 & & $65.60(62.65-87.35)$ \\
17 & & $89.90(77.13-123.05)$ \\
18 & & $90.10(78.80-124.13)$ \\
19 & & $92.15(80.75-126.50)$ \\
20 & & $126.60(109.43-143.78)$ \\
\hline
\end{tabular}

Legend: IQR interquartile range.

The amount of blood sampling during the total length of stay in relation to birth weight [mL/kg birth weight, median (IQR)] was $16.42 \mathrm{~mL}$ (IQR 9.86-32.65 mL) for the whole group; $12.78 \mathrm{~mL}$ (IQR 8.15-17.35 mL) for non-transfused infants and $39.42 \mathrm{~mL}$ (IQR 29.33-73.95 mL) for transfused infants (Figure 1).

The mean initial hematocrit in non-transfused neonates with $52.6 \%$ was significantly higher compared to $47.0 \%$ in neonates requiring transfusion during hospital stay $(p<0.001)$, whereas the hematocrit at discharge was not statistically different between the two groups $(31.3 \%$ vs. $30.4 \%, p=0.34)$ (Figure 1 ).

The time course of cumulative iatrogenic losses by blood sampling is presented in Table 4 and Figure 2A,B. The cumulative blood sampling volume was significantly different between patients requiring a transfusion and non-transfused patients. The time course of hematocrit is shown in Figure 2C.

There was a significant correlation between cumulative blood sampling volume and cumulative blood transfusion volume (Figure 3).

An analysis of the relative contribution of iatrogenic blood losses in the study sample of neonates treated in our unit is given in Figure 4. 

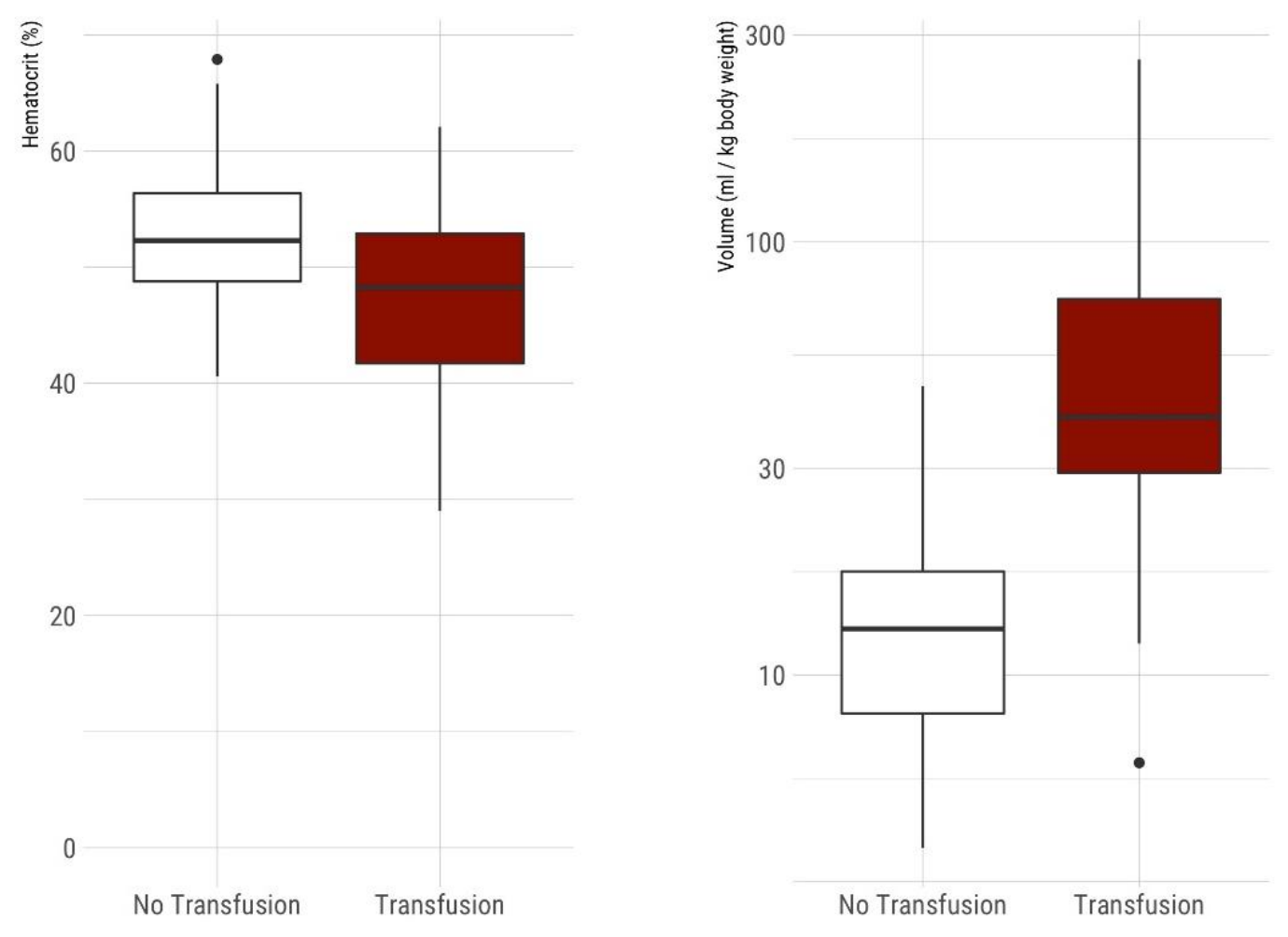

Figure 1. (Left) Comparison of hematocrit on admission between non-transfused and transfused VLBW infants. Boxplots show median, IQR, 95\% confidence intervals, and outliers. The mean initial hematocrit in non-transfused neonates with $52.6 \%$ was significantly higher compared to $47.0 \%$ in neonates requiring at least one transfusion during hospital stay $(p<$ 0.001). (Right) Comparison of cumulative blood sampling volume in VLBW infants during their hospital stay [mL/ $\mathrm{kg}$ body weight at birth] between non-transfused and transfused VLBW neonates. Boxplots show median, IQR, 95\% confidence intervals and outliers, $y$-axis logarithmic scale. Non-transfused neonates $(n=90)$ had significantly less median blood sampling volume $12.78 \mathrm{~mL}$ (IQR 8.15-17.35 mL) compared to neonates with one or more red blood cell transfusions during their hospital stay $(n=42)$ with a median cumulative sampling volume of 39.42 mL (IQR 29.33-73.95 mL).

Table 4. Chi-Square Test statistics for demographic and outcome factors associated with transfusions, factors ordered in ascending likelihood ratio for the necessity of red blood cell transfusion.

\begin{tabular}{ccc}
\hline Factor & $\begin{array}{c}\text { Likelihood Ratio } \\
\text { (Fisher's Exact Test) }\end{array}$ & $p$ \\
\hline Sex & 0.127 & 0.852 (n.s.) \\
Multiple gestation & 0.127 & 0.852 (n.s.) \\
Delivery mode & 0.140 & 0.740 (n.s.) \\
IVH & 3.216 & 0.081 (n.s.) \\
BPD & 7.165 & $0.012^{*}$ \\
Mortality & 7.165 & $0.012^{*}$ \\
ROP & 7.165 & $0.012^{*}$ \\
NDA treated operatively & 9.432 & $0.009^{*}$ \\
PDA treated medically & 9.432 & $0.009^{*}$ \\
Sepsis/Infection & 12.892 & $0.000^{*}$ \\
Gestational age & 30.087 & $0.000^{*}$ \\
Length of stay & 92.743 & $0.001 *$ \\
Birth weight & 131.353 & $0.000^{*}$ \\
\hline
\end{tabular}

Legend: n.s. no significance; ${ }^{*} p<0.05$. LOS length of stay; IVH intraventricular hemorrhage (grade 3 and 4); BPD bronchopulmonary dysplasia; ROP retinopathy of prematurity; PDA persistent arterial duct; NEC necrotizing enterocolitis. 

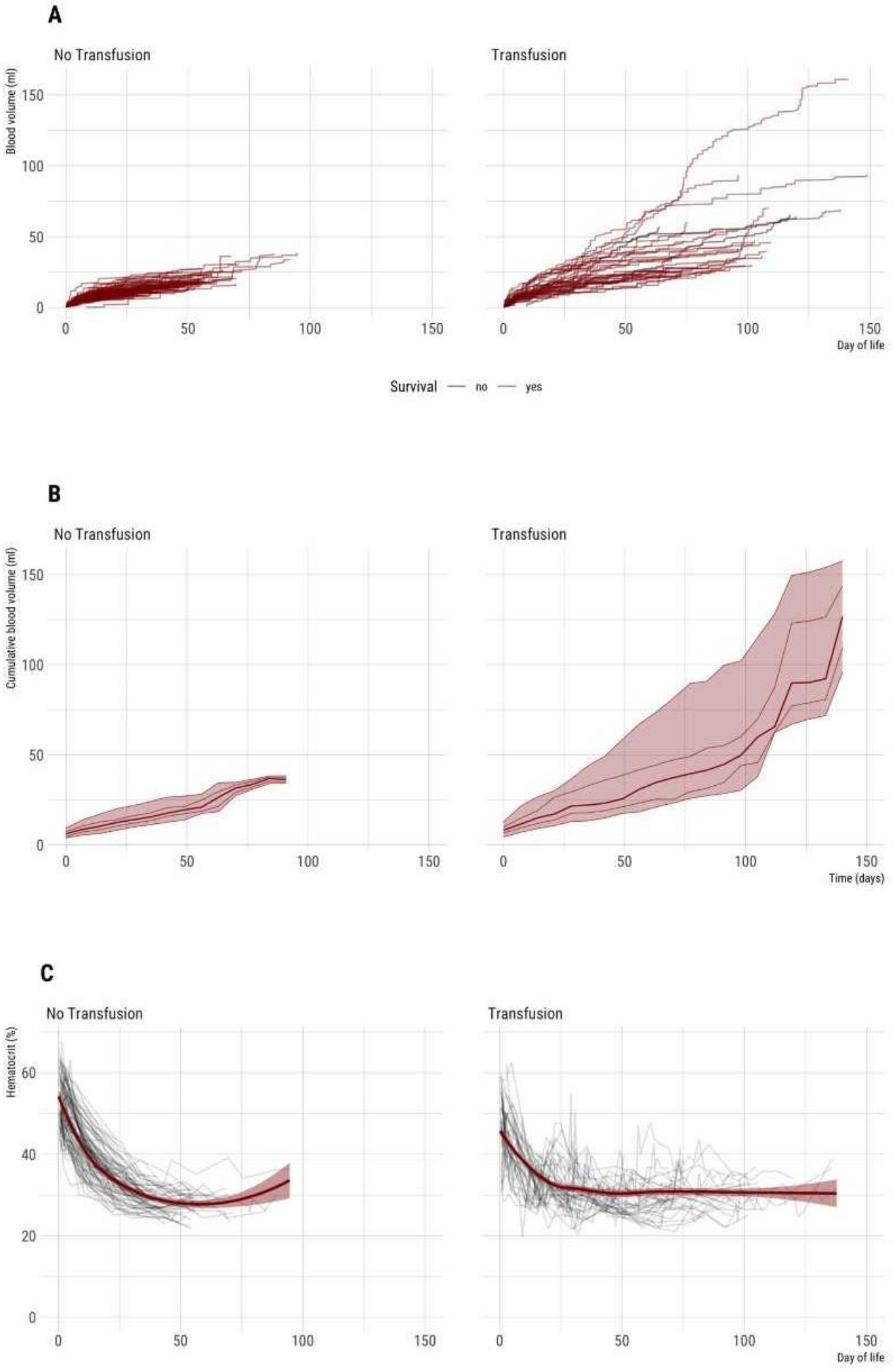

Figure 2. (A-C) Time course of cumulative blood sampling volume and hematocrit during entire hospital stay $(n=132$ VLBW neonates included). Left: Non-transfused neonates $(n=90)$. Right: Neonates with one or more red cell transfusions $(n=42)$. (A) Absolute cumulative blood sampling volume $[\mathrm{mL}]$ over time. Each line represents an individual patient. (B) Median and percentiles (percentiles 5, 25, 50 75, 95) are given for a minimum of 3 patients per week, therefore plot truncated at 20 weeks. (C) Time course of hematocrit. Each grey line represents an individual patient. The dark red lines show smoothed average hematocrit, the dark red transparent ribbon the $95 \% \mathrm{CI}$ of mean over time. 

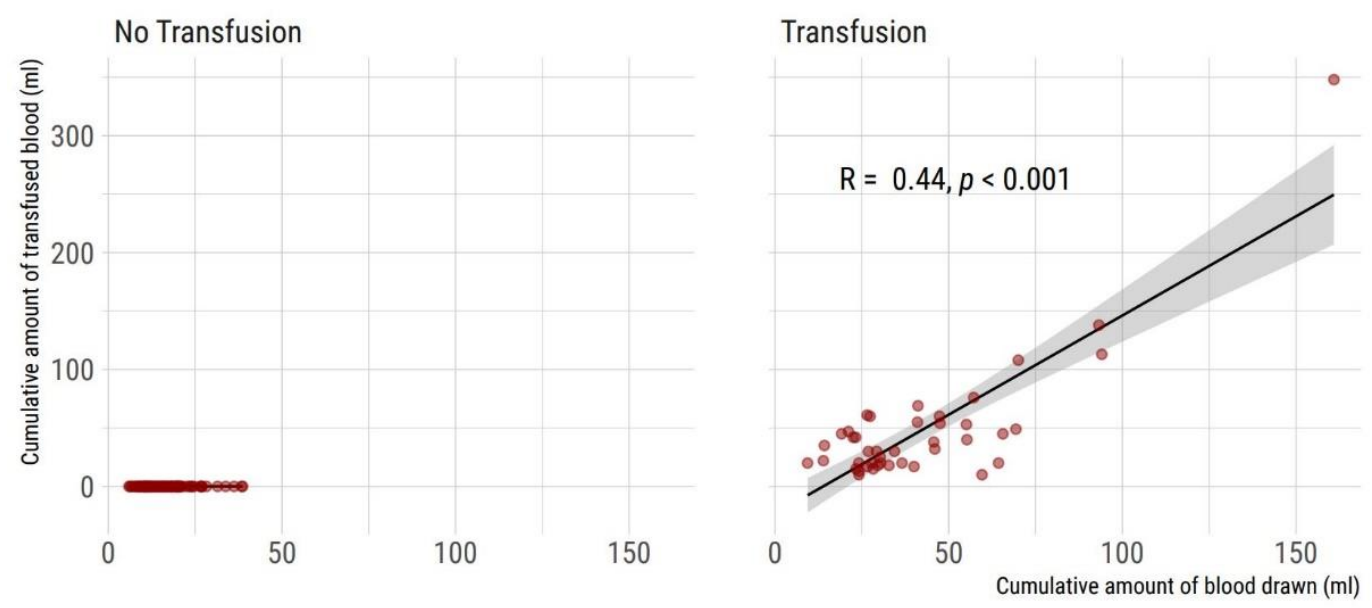

Figure 3. Correlation of cumulative blood sampling volume and cumulative amount of transfused blood during entire hospital stay ( $n=132$ VLBW neonates included). (Left) Non-transfused neonates $(n=90)$. (Right) Neonates with one or more red cell transfusions $(n=42)$. Two-sided Spearman's rank correlation coefficient rho and 95\% CI is given.

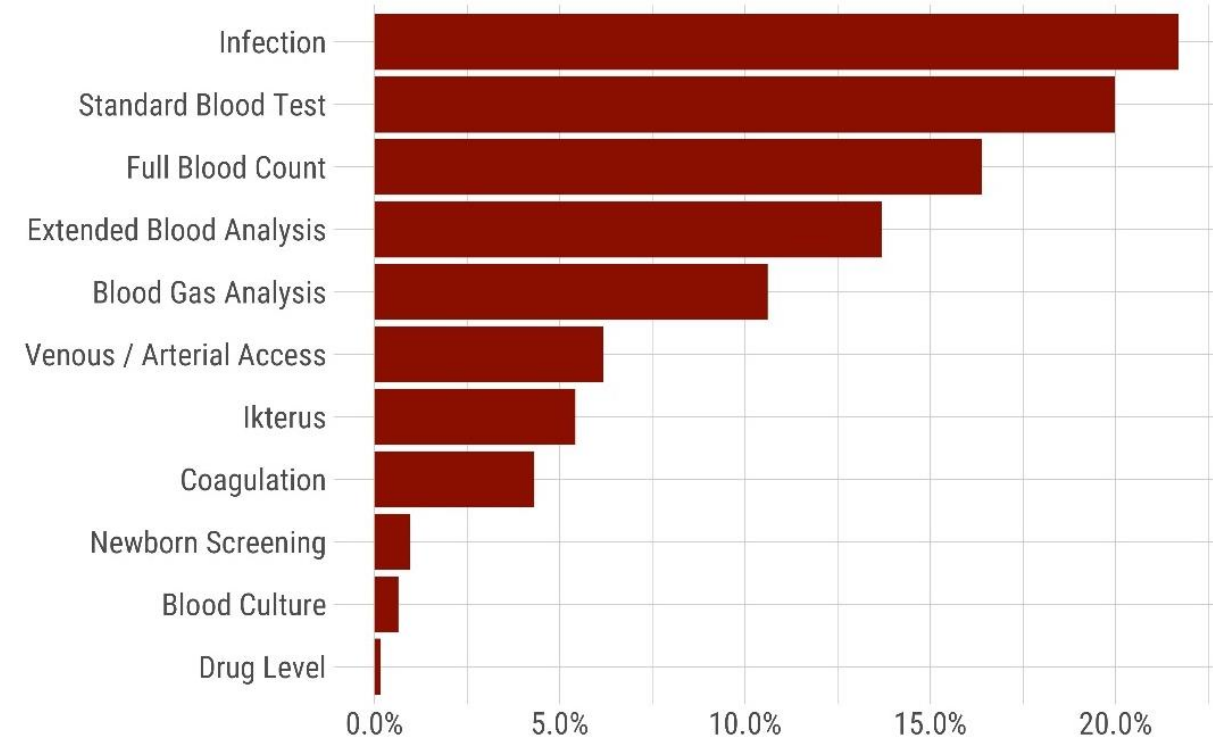

Figure 4. Relative amount [\%] of iatrogenic blood loss during the hospital stay $(n=132$ VLBW included neonates into the analysis). The bars represent the cumulative relative amount of blood loss associated with different laboratory investigations: Infection (sample including IL6), standard blood test (sample with C-reactive protein), full blood count, extended blood analysis (liver and renal function tests), blood gas analysis, losses during vascular access, icterus (bilirubin and liver function test), coagulation (clotting studies), newborn screening (neonatal newborn screening), blood culture, drug level.

\subsection{Risk Factors for Necessity of Transfusion}

Demographic parameters associated with the necessity for erythrocyte transfusion were birth weight, gestational age, and length of stay, whereas sex, delivery mode, and multiple gestations were not associated with an increased risk of a transfusion requirement. Outcome parameters significantly associated with the necessity for erythrocyte transfusion were sepsis/infection, PDA, NEC, ROP, fatal outcome. In contrast, IVH was not significantly associated with transfusions (Table 4).

A generalized logistic model, including time on invasive ventilation, the total amount of blood sampling, first hematocrit, and gestational age was calculated in order to identify independent risk factors for red blood cell transfusion during the hospital stay. The 
model identified the total amount of blood sampling and first hematocrit as independent predictors for a blood transfusion (Figure 5).

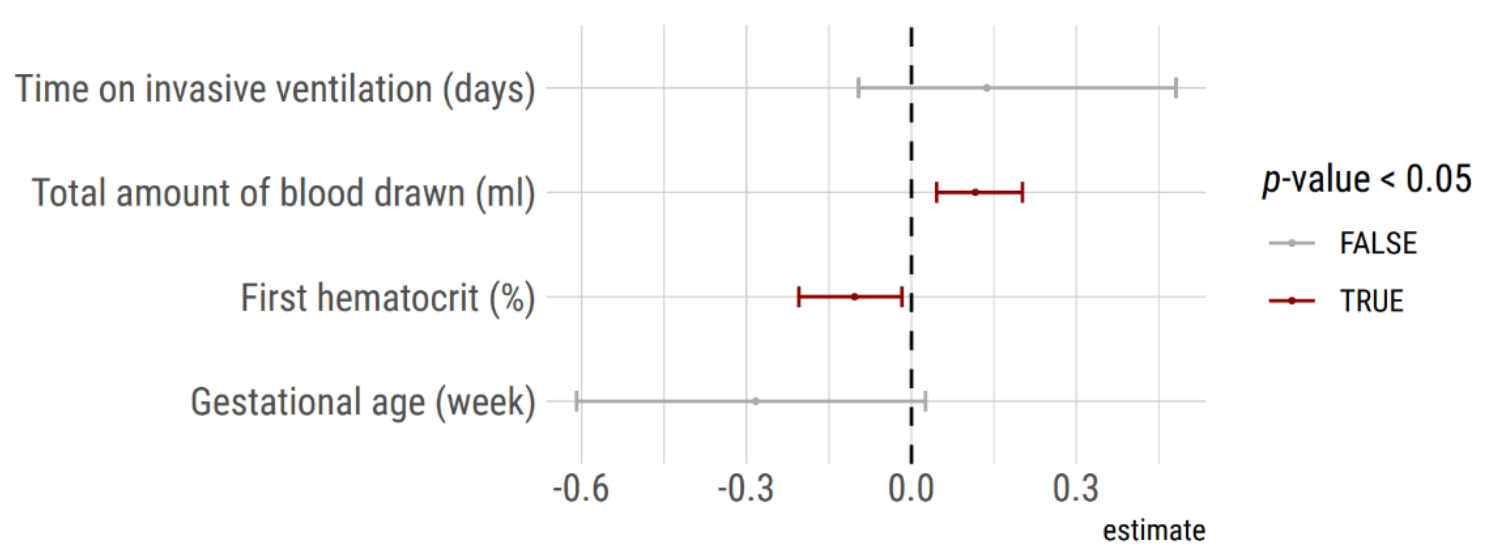

Figure 5. Predictors of transfusion deduced from a generalized logistic model. Cumulative blood sampling volume and hematocrit on admission were significant independent predictors of red blood cell transfusion during the hospital stay in the 132 VLBW included neonates into the analysis.

\section{Discussion}

This single-center retrospective study analyzed the amount of iatrogenic blood sampling and subsequent blood loss and requirements for packed red cell transfusions in VLBW infants during their entire hospital stay. The sample cohort comprised a non-selected crosssectional and consecutive longitudinal group of VLBW neonates.

The median absolute amount of blood sampling during the initial four weeks of life was $16.5 \mathrm{~mL}$ (IQR 12.3-21.1 mL). The cumulative blood sampling volume was comparable to a recent publication on neonatal blood sampling in VLBW infants with a median blood loss of $19.6 \mathrm{~mL}$ during the first 28 days [8] and lower than in historical data [6,7]. Our unit strives to keep usage of umbilical vascular catheters restrictive and as short as possible. This may also contribute to a relatively low iatrogenic blood loss [9].

Demographic factors such as lower birth weight, lower gestational age, and longer length of stay were significantly associated with the necessity for erythrocyte transfusion, as well as several adverse neonatal outcome parameters (sepsis/infection, PDA, NEC, ROP, death). Thus, smaller VLBW patients with higher morbidity had a higher risk of receiving a transfusion.

In addition, a generalized logistic model identified both the cumulative amount of blood sampling (in $\mathrm{mL} / \mathrm{kg}$ body weight) and the initial hematocrit as significant independent predictors of transfusion in the VLBW infants of our sample cohort.

The study finding of a higher hematocrit at birth in the group of non-transfused neonates supports the recommendations regarding delayed cord clamping at birth $[3,4]$. In a meta-analysis, delayed cord clamping increased the hematocrit at birth by $2.73 \%$, resulting in a $10 \%$ reduction of red cell transfusions [4]. In our study, the initial hematocrit of non-transfused children was $11.9 \%$ higher than in transfused children ( $52.6 \%$ vs. $47.0 \%$ ). Neonatal data showed an inverse correlation between hemoglobin at birth and the necessity for red blood cell transfusions during the hospital stay in VLBW neonates [14].

The study finding of a positive correlation between the amount of cumulative blood sampling and cumulative blood transfusion requirement implies, that all measures to spare blood, which is a valuable and limited resource for the patient, should be implemented $[6-15,19]$. Depending on local neonatal and laboratory practice the relative amount of iatrogenic blood losses may be distributed differently compared to our study sample (Figure 4) [10]. Neonatal patient blood management may include the use of umbilical cord or placental blood for admission laboratory values [13]. In addition, storage of maternal blood for ordering and crossmatching of blood products may minimize the amount of 
blood required for laboratory analyses. Setting point of care devices to minimal blood volumes, use of non-invasive monitoring methods, avoidance of "routine" blood sampling, strict indication, and supervision of blood tests by experienced personnel may help to avoid iatrogenic blood losses $[9,12]$. Cumulative documentation of blood draw volumes, possibly based on an automated calculation derived from a PDMS system, might also help raise neonatal team awareness in avoiding iatrogenic blood loss.

Perinatal medicine is well aware of the issue of placental transfusion at birth and the possible benefits of delayed cord clamping - providing additional blood volume to neonates $[1-5,20,21]$ as part of initial neonatal management. The intention of this study is to emphasize the importance of the opposite side of the balance, i.e., avoidance of iatrogenic blood loss, especially in VLBW preterm infants as a part of good neonatal blood management $[6-15,19]$.

Strengths and limitations: This analysis includes the entire hospital stay of a-compared to previously published data [6-9] —-larger sample cohort of VLBW neonates over a longer time course. Blood sampling volumes were retrospectively deduced from the PDMS based on the locally minimally required amount of blood for standard laboratory investigations. This implies a complete cumulative capture of all blood samples, but potentially underestimating blood sampling volumes in case of overfilled blood tubes. The unit policy adheres to restrictive transfusion triggers [16-18], but each transfusion was indicated at the physician's discretion in charge, implying a potential bias in the transfusion trigger. Statistical statements in association with neonatal morbidity are only possible to a limited extent, as the absolute number of patients with complications was low. Nevertheless, we identified the initial hematocrit and the total blood sampling volume as independent predictors for red blood cell transfusion in our patient sample.

\section{Conclusions}

In a patient sample of 132 VLBW neonates, cumulative iatrogenic blood losses during the entire hospital stay and the initial hematocrit were significant independent predictors for the necessity of packed red cell transfusions. Therefore, iatrogenic blood loss should be limited to a minimum in the interest of good patient blood management.

Author Contributions: Conceptualization, A.A., D.S. and M.E.B.; methodology, A.A., P.D. and M.E.B.; software, P.D. and M.E.B.; validation, A.A., P.D. and M.E.B.; formal analysis, A.A., P.D., C.U.E. and M.E.B.; investigation, A.A., P.D. and M.E.B.; resources, D.S.; data curation, A.A. and P.D.; writing—original draft preparation, M.E.B.; writing—review, editing, visualization, A.A., P.D., C.U.E., D.S. and M.E.B.; supervision, not applicable; project administration, M.E.B. Funding acquisition, no external funding. All authors have read and agreed to the published version of the manuscript.

Funding: This research received no external funding.

Institutional Review Board Statement: The study was conducted according to the guidelines of the Declaration of Helsinki. Ethical review and approval were waived for this study by the local Ethics Committee (Ethik-Kommission der Ärztekammer Hamburg) in concordance with the local Hamburg Chamber Act for the Medical Professions and Professional Code of Conduct for Hamburg Physicians (WF-075/21, 29 March 2021), as the retrospective study handled and presented totally anonymized data.

Informed Consent Statement: Patient consent was waived (Ethik-Kommission der Ärztekammer Hamburg, WF-075/21, 29 March 2021, see above IRB statement).

Data Availability Statement: The data are not publicly available due to patient privacy reasons.

Conflicts of Interest: The authors declare no conflict of interest.

\section{References}

1. Hooper, S.B.; Pas, A.T.; Lang, J.; van Vonderen, J.; Roehr, C.C.; Kluckow, M.; Gill, A.; Wallace, E.; Polglase, G. Cardiovascular transition at birth: A physiological sequence. Pediatr. Res. 2015, 77, 608-614. [CrossRef]

2. Yao, A. Distribution of blood between infant and placenta after birth. Lancet 1969, 294, 871-873. [CrossRef] 
3. Madar, J.; Roehr, C.C.; Ainsworth, S.; Ersdal, H.; Morley, C.; Rüdiger, M.; Skåre, C.; Szczapa, T.; Pas, A.T.; Trevisanuto, D.; et al. European Resuscitation Council Guidelines 2021: Newborn resuscitation and support of transition of infants at birth. Resuscitation 2021, 161, 291-326. [CrossRef]

4. Fogarty, M.; Osborn, D.A.; Askie, L.; Seidler, A.L.; Hunter, K.; Lui, K.; Simes, J.; Tarnow-Mordi, W. Delayed vs early umbilical cord clamping for preterm infants: A systematic review and meta-analysis. Am. J. Obstet. Gynecol. 2018, 218, 1-18. [CrossRef] [PubMed]

5. Katheria, A.; Reister, F.; Essers, J.; Mendler, M.; Hummler, H.; Subramaniam, A.; Carlo, W.; Tita, A.; Truong, G.; Davis-Nelson, S.; et al. Association of Umbilical Cord Milking vs Delayed Umbilical Cord Clamping With Death or Severe Intraventricular Hemorrhage Among Preterm Infants. JAMA 2019, 322, 1877-1886. [CrossRef] [PubMed]

6. Nexø, E.; Christensen, N.C.; Olesen, H. Volume of blood removed for analytical purposes during hospitalization of lowbirthweight infants. Clin. Chem. 1981, 27, 759-761. [CrossRef]

7. Obladen, M.; Sachsenweger, M.; Stahnke, M. Blood sampling in very low birth weight infants receiving different levels of intensive care. Eur. J. Nucl. Med. Mol. Imaging 1988, 147, 399-404. [CrossRef]

8. Counsilman, C.E.; Heeger, L.E.; Tan, R.; Bekker, V.; Zwaginga, J.J.; Pas, A.T.; Lopriore, E. Iatrogenic blood loss in extreme preterm infants due to frequent laboratory tests and procedures. J. Matern. Neonatal Med. 2021, 34, 2660-2665. [CrossRef] [PubMed]

9. Carroll, P.D.; Zimmerman, M.B.; Nalbant, D.; Gingerich, E.L.; An, G.; Cress, G.A.; Veng-Pedersen, P.; Widness, J.A. Neonatal Umbilical Arterial Catheter Removal Is Accompanied by a Marked Decline in Phlebotomy Blood Loss. Neonatology 2020, 117, 294-299. [CrossRef] [PubMed]

10. Madsen, L.P.; Rasmussen, M.K.; Bjerregaard, L.L.; Nøhr, S.B.; Ebbesen, F. Impact of blood sampling in very preterm infants. Scand. J. Clin. Lab. Investig. 2000, 60, 125-132. [CrossRef] [PubMed]

11. Puia-Dumitrescu, M.; Tanaka, D.T.; Spears, T.G.; Daniel, C.J.; Kumar, K.R.; Athavale, K.; Juul, S.E.; Smith, P.B. Patterns of phlebotomy blood loss and transfusions in extremely low birth weight infants. J. Perinatol. 2019, 39, 1670-1675. [CrossRef]

12. Jakacka, N.; Snarski, E.; Mekuria, S. Prevention of Iatrogenic Anemia in Critical and Neonatal Care. Adv. Clin. Exp. Med. 2016, 25, 191-197. [CrossRef] [PubMed]

13. Carroll, P.D.; Christensen, R.D. New and underutilized uses of umbilical cord blood in neonatal care. Matern. Health Neonatol. Perinatol. 2015, 1, 16. [CrossRef] [PubMed]

14. Ekhaguere, O.A.; Jr, F.H.M.; Bell, E.; Prakash, N.; Widness, J.A. Predictive factors and practice trends in red blood cell transfusions for very-low-birth-weight infants. Pediatr. Res. 2016, 79, 736-741. [CrossRef] [PubMed]

15. Crighton, G.L.; New, H.V.; Liley, H.G.; Stanworth, S.J. Patient blood management, what does this actually mean for neonates and infants? Transfus. Med. 2018, 28, 117-131. [CrossRef] [PubMed]

16. Whyte, R.; Kirpalani, H. Low versus high haemoglobin concentration threshold for blood transfusion for preventing morbidity and mortality in very low birth weight infants. Cochrane Database Syst. Rev. 2011, 11. [CrossRef]

17. Howarth, C.; Banerjee, J.; Aladangady, N. Red Blood Cell Transfusion in Preterm Infants: Current Evidence and Controversies. Neonatology 2018, 114, 7-16. [CrossRef] [PubMed]

18. Franz, A.R.; Engel, C.; Bassler, D.; Rüdiger, M.; Thome, U.H.; Maier, R.F.; Krägeloh-Mann, I.; Kron, M.; Essers, J.; Bührer, C.; et al. Effects of Liberal vs Restrictive Transfusion Thresholds on Survival and Neurocognitive Outcomes in Extremely Low-Birth-Weight Infants. JAMA 2020, 324, 560-570. [CrossRef]

19. Whitehead, N.S.; Williams, L.O.; Meleth, S.; Kennedy, S.M.; Ubaka-Blackmoore, N.; Geaghan, S.M.; Nichols, J.H.; Carroll, P.; McEvoy, M.T.; Gayken, J.; et al. Interventions to prevent iatrogenic anemia: A Laboratory Medicine Best Practices systematic review. Crit. Care 2019, 23, 1-11. [CrossRef]

20. Katheria, A.C.; Lakshminrusimha, S.; Rabe, H.; McAdams, R.; Mercer, J.S. Placental transfusion: A review. J. Perinatol. 2017, 37, 105-111. [CrossRef] [PubMed]

21. Rabe, H.; Gyte, G.M.; Díaz-Rossello, J.L.; Duley, L. Effect of timing of umbilical cord clamping and other strategies to influence placental transfusion at preterm birth on maternal and infant outcomes. Cochrane Database Syst. Rev. 2019, 2019 , CD003248. [CrossRef] [PubMed] 